\title{
WOODLAND MAPPING AT SINGLE-TREE LEVELS USING OBJECT-ORIENTED CLASSIFICATION OF UNMANNED AERIAL VEHICLE (UAV) IMAGES
}

\author{
A. Chenari ${ }^{\text {a, }}$ Y. Erfanifard ${ }^{\text {a, } *}$, M. Dehghani ${ }^{\text {b }}$, H.R. Pourghasemi ${ }^{\text {a }}$ \\ ${ }^{a}$ Dept. of Natural Resources and Environment, College of Agriculture, Shiraz University, Shiraz, Iran - \\ afrooz.chenari71@gmail.com, erfanifard@shirazu.ac.ir,hr.pourghasemi@shirazu.ac.ir \\ ${ }^{\mathrm{b}}$ Dept. of Civil and Environmental Engineering, School of Engineering, Shiraz University, Shiraz, maryamdehghani@ shirazu.ac.ir
}

KEY WORDS: Crown area, Object-oriented classification, Tree map, Unmanned aerial vehicle, Woodland.

\begin{abstract}
:
Remotely sensed datasets offer a reliable means to precisely estimate biophysical characteristics of individual species sparsely distributed in open woodlands. Moreover, object-oriented classification has exhibited significant advantages over different classification methods for delineation of tree crowns and recognition of species in various types of ecosystems. However, it still is unclear if this widely-used classification method can have its advantages on unmanned aerial vehicle (UAV) digital images for mapping vegetation cover at single-tree levels. In this study, UAV orthoimagery was classified using object-oriented classification method for mapping a part of wild pistachio nature reserve in Zagros open woodlands, Fars Province, Iran. This research focused on recognizing two main species of the study area (i.e., wild pistachio and wild almond) and estimating their mean crown area. The orthoimage of study area was consisted of 1,076 images with spatial resolution of $3.47 \mathrm{~cm}$ which was georeferenced using 12 ground control points $(\mathrm{RMSE}=8 \mathrm{~cm}$ ) gathered by real-time kinematic $(\mathrm{RTK})$ method. The results showed that the UAV orthoimagery classified by object-oriented method efficiently estimated mean crown area of wild pistachios $\left(52.09 \pm 24.67 \mathrm{~m}^{2}\right)$ and wild almonds $\left(3.97 \pm 1.69 \mathrm{~m}^{2}\right)$ with no significant difference with their observed values $(\alpha=0.05)$. In addition, the results showed that wild pistachios (accuracy of 0.90 and precision of 0.92 ) and wild almonds (accuracy of 0.90 and precision of 0.89 ) were well recognized by image segmentation. In general, we concluded that UAV orthoimagery can efficiently produce precise biophysical data of vegetation stands at single-tree levels, which therefore is suitable for assessment and monitoring open woodlands.
\end{abstract}

\section{INTRODUCTION}

Biophysical characteristics of vegetation cover play an important role in exploring ecological and socio-economic effects of vegetation in open woodlands. In addition, these characteristics may influence on ecosystem patterns and processes since essential nutrients and moisture are concentrated beneath canopy of plants in these open woodlands with sparse vegetation cover (Korhonen et al., 2006; Wallace et al., 2008; Chianucci et al., 2016).

Similar to other woodlands, Zagros open woodlands in western Iran are very important on ecological (such as wildlife habitat, soil and water conservation) and socio-economic (for example, dependence of rural communities and nomads to byproducts) attributes that makes it essential to prevent their existence to be at risk. An ongoing challenge to sustainable management of these valuable woodlands; however, is costeffective and accurate monitoring of spatial and temporal changes in vegetation cover. Assessment and monitoring of species at single-tree level in such ecosystems typically concentrate on a number of parameters such as composition of species individuals, abundance of species offsprings, and biophysical characteristics such as crown area and branching architecture. As mentioned above, biophysical characteristics and in particular crown area and density (i.e., number of individuals per unit area), is strongly associated with establishment and growth of recruits in these open arid and semi-arid woodlands.

Regarding to the importance of the mentioned biophysical characteristics of vegetation, mapping these characteristics has become one of the major goals of open woodland mensuration
(Chopping et al., 2008). There are various types of methods that have been developed to assess the mentioned characteristics by field measurements (Rautiainen et al., 2005; Korhonen et al., 2006; Hanberry et al., 2012). However, remotely sensed imagery from spaceborne and/or airborne platforms are preferred to quantify canopy cover and density in different forest ecosystems by previous researchers due to their less costs and time-consumption and more practical for large ecosystems, e.g. Zagros semi-arid woodlands in western Iran (Carreiras et al., 2006; Gleason and Im, 2011; Feret and Asner, 2012; Yang et al., 2012; Rezayan and Erfanifard, 2016). The outcome of classification of remotely sensed imagery is a thematic map exhibiting the spatial distribution of plants and their corresponding crowns within the studied environment (Schowengerdt, 2007; Panta et al., 2008).

Remote sensing datasets provide an outstanding way to obtain thematic maps of vegetation cover from local to global scales, while most of these datasets obtained by spaceborne platforms are not appropriate to map biophysical characteristics of single plants in open woodlands because of their low or medium spatial resolution as explored by Colomina and Molina (2014). On the one hand, it is so expensive to apply satellite data with very high spatial resolution (e.g., WorldView-3 with $30 \mathrm{~cm}$ spatial resolution), and on the other hand, datasets acquired by digital cameras (such as UltraCam-D) and airborne platforms are not available in all places (Chianucci et al., 2016). Therefore, it seems necessary to use remotely sensed datasets with appropriate spatial resolution for vegetation mapping of individual plants that are available with reasonable cost and complexity. Unmanned aerial vehicles (UAVs), as a result of recent advances in remote sensing, can combine temporal and 
spatial resolutions to provide appropriate datasets for mapping forested areas at single-tree levels. Diaz-Varela et al. (2014) mentioned that UAVs are attractive and flexible tools for mapping and monitoring of various aspects of environment. Progress made in internal sensors, reduction of costs, more flexibility compared to spaceborne and airborne platforms, and precise GPS embedded are some of unique advantages that have enhanced the application of UAVs in a wide range of subjects. Recent studies have exhibited the feasibility of using UAVs in monitoring (Torres-Sanchez et al., 2015; Vega et al., 2015; Mlambo et al., 2017) and measurement of characteristics plant species (Chianucci et al., 2016; McNeil et al., 2016; Ivosevic et al., 2017). In contrary, relatively few investigations have studied the applicability of orthoimages taken by UAVs for mapping biophysical characteristics of trees and shrubs at single-tree levels. Kuzmin et al. (2016) used UAV imagery to recognize tree species in a mixed boreal forest with overall accuracy of $82 \%$. In addition, UAVs are very interesting instruments that hold great potential for mapping individual plants in open woodlands.

UAVs take images at very high spatial resolution which makes precise recognition of features possible. As the spatial resolution of imagery increases, the heterogeneity of pixels may lead to salt-and-pepper effect in pixel-based classification techniques. Previous studies revealed that it is so difficult to accurately distinguish features on images with very high spatial resolution by pixel-based techniques (Blaschke et al., 2000; Blaschke and Strobl, 2001). Taking into account the disadvantages of pixel-based techniques, many researchers have applied object-oriented classification techniques to recognize features on images with very high spatial resolution (Ouyang et al., 2011). To explore efficiency of object-oriented classification method to map single species in mixed stands on very high resolution datasets, it needs to be tested on UAV orthoimagery.

In this study, we hypothesize that UAV orthoimages can be implemented to map vegetation spatial arrangement of plant species in Zagros open woodlands. It was also hypothesized that object-oriented classification method on UAV orthoimagery is efficient to recognize type of species of individual plants in mixed stands. The main objective of the current study is to delineate crown area and spatial position of individual wild pistachio trees and wild almond shrubs in a mixed stand using object-oriented classification method on UAV orthoimagery.

\section{METHODOLOGY}

\subsection{Study Area}

Zagros open woodlands cover a vast area of Zagros Mountain ranges stretching from Piranshahr (Western Azerbaijan Province), northwestern Iran, to the vicinity of Firoozabad (Fars Province) in southwestern Iran, having an average length and width of 1,300 and $200 \mathrm{~km}$, respectively (Fig. 1a). The study area classified as semi-arid based on Ambreje method, Zagros Woodlands cover 5 million hectares and consist $40 \%$ of Iran's forests.

The most important and widespread species is oak with three species (i.e. Quercus brantii var. persica, $Q$. libani, and $Q$. infectoria) that consist $85 \%$ of Zagros open woodlands. These oak species often form pure stands and sometimes, are mixed with wild pistachio (Pistacia spp.) and wild almond (Amygdalus spp.) (Owji and Hamzepour, 2012; Sagheb Talebi et al. 2014).

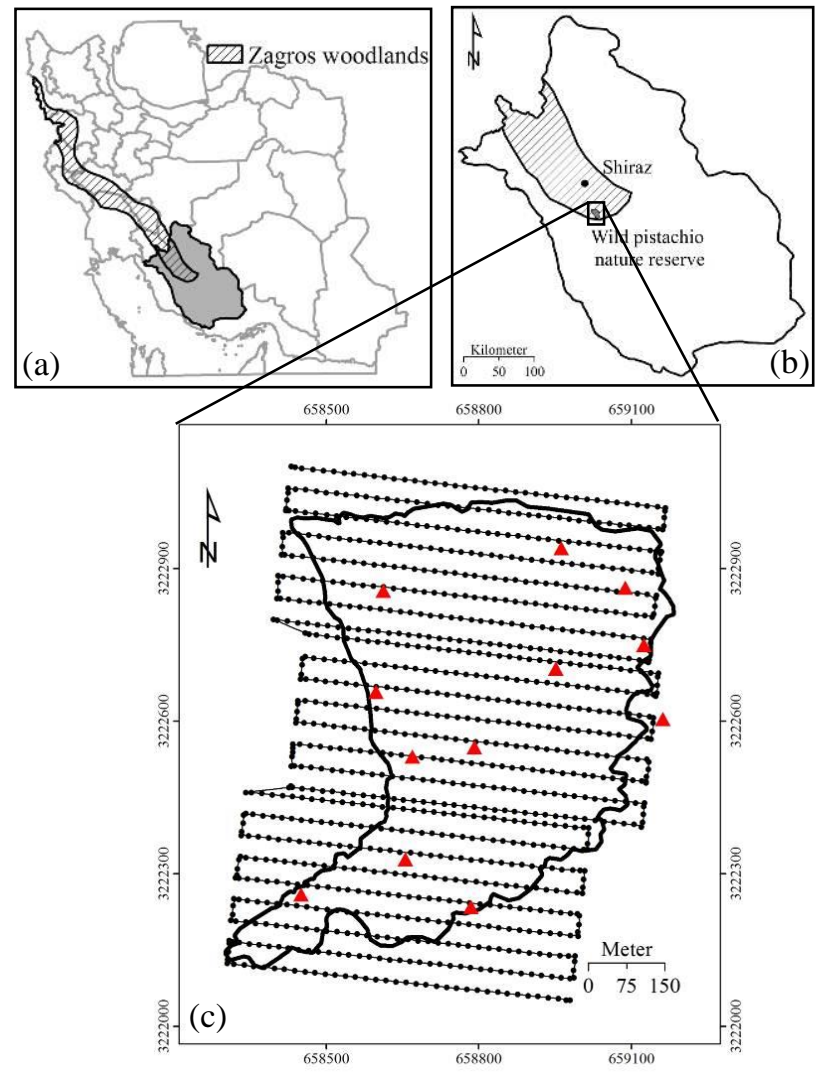

Figure 1. Map identifying the 45-ha study area in wild pistachio nature reserve (a) in Zagros woodlands of Fars province (a) and extent of Zagros woodlands in West Iran (b). The study area: filled circles and black lines show flight plan and red triangles indicate the location of ground control points (c).

The study site with 45 ha area is located in wild pistachio nature reserve in Fars Province, Iran (Fig. 1b), between $52^{\circ} 30^{\prime}$ to $52^{\circ} 40^{\prime} \mathrm{E}$ and $29^{\circ} 00^{\prime}$ to $29^{\circ} 15^{\prime} \mathrm{N}$ (Fig. 1c). The minimum and maximum elevations are 1,859 and $1,935 \mathrm{~m}$ a.s.l., respectively. The mean annual precipitation and temperature are $383 \mathrm{~mm}$ and $27.6{ }^{\circ} \mathrm{C}$, respectively (Owji and Hamzepour, 2012). The study site was fully covered by wild pistachio (Pistacia atlantica var. mutica) (Fig. 2) as the second most frequent tree species in Zagros Woodlands, accompanied by wild almond shrubs (Fig. 3).

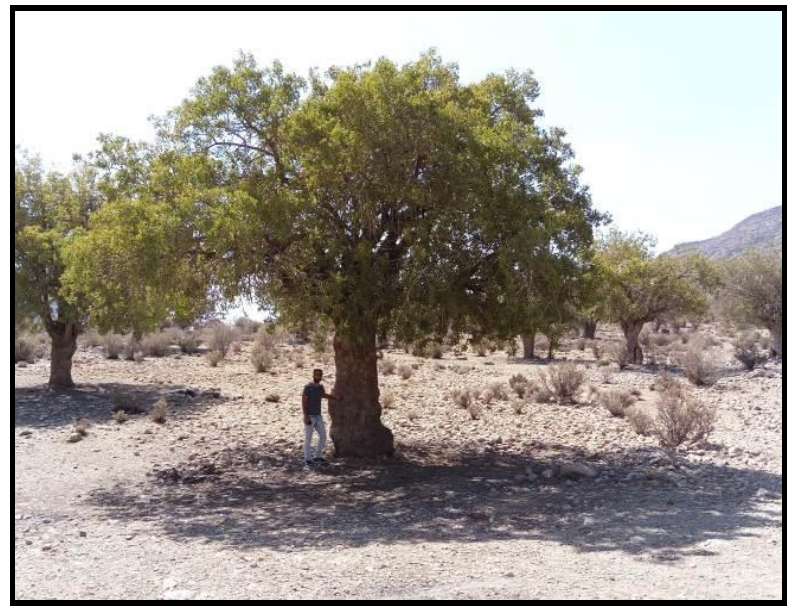

Figure 2. A wild pistachio tree within the study site (Photo taken by A. Chenari) 


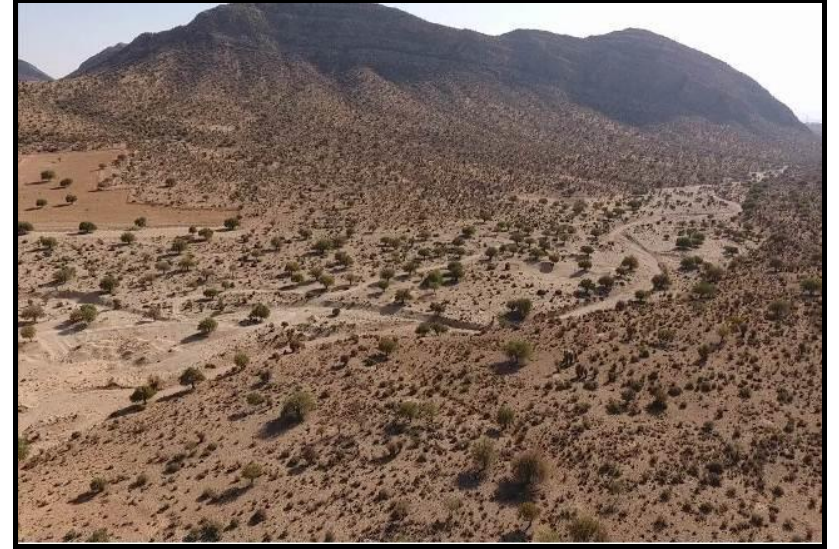

Figure 3. The study site was covered by wild pistachio trees and wild almond shrubs (Photo taken by Phantom-4 UAV).

\subsection{UAV Imagery}

The UAV applied in this study was DJI Phantom-4 quadcopter equipped with a digital camera with a $1 / 2.3$ inch CMOS sensor and a size of 3,000 × 4,000 pixels (Fig. 4a). It has a weight of about $1,380 \mathrm{~g}$ including a digital camera, battery, and GPS. The maximum flight time length was about $28 \mathrm{~min}$. If the necessary parameters, i.e., area of interest, desired ground resolution, longitudinal overlap are determined; the UAV automatically calculates the number of strips and flight height (Table 1). UAV take-off and landing are managed and monitored by operator through remote controller. In addition, operator can control the UAV during flight by means of remote controller up to maximum distance of $5 \mathrm{~km}$ from the vehicle. All RGB (Red-Green-Blue) images were acquired in jpeg format with the digital camera set in automatic mode in clear and calm climatic conditions at noon to reduce shadow effect and wind effects on the flight mission and collected images.

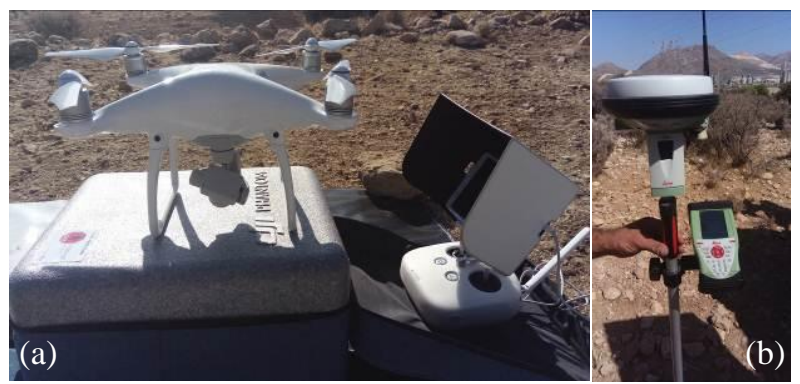

Figure 4. The DJI Phantom-4 unmanned aerial vehicle was used for image acquisition in this study (a), Leica GS10 global position system with dual frequency was applied to collect ground control points (b) (Photo taken by A. Chenrai).

\begin{tabular}{|l|c|}
\hline Parameters of flight plan & Values \\
\hline Area of interest & $45 \mathrm{ha}$ \\
Desired ground resolution & $3.5 \mathrm{~cm}$ \\
Longitudinal overlap & $70 \%$ \\
The number of strips & 25 strips \\
Flight height & $70 \mathrm{~m}$ \\
\hline
\end{tabular}

Table 1. The parameters of flight plan of Phantom-4 UAV that was used in this study.
The collected images were automatically matched using an algorithm that identifies tie points which were also use to retrieve the parameters of orientation necessary in aerial triangulation. Moreover, 12 ground control points (GCPs) (Fig. 1a) collected by Leica GS10 GPS with dual frequency (Fig. 4b) were used in the triangulation process (www.dji.com).

\subsection{Image Classification}

The main goal of classification of a remotely sensed image is to automatically assign consistent groups of pixels into appropriate themes or classes. In general, the spectral content of each pixel is applied as the numerical basis for classification. Pixel-based classification techniques use spectral information of each pixel or digital numbers which are based on spectral reflectance and emittance of features to categorize classes (Schowengerdt, 2007). Although, pixel-based classification techniques have some advantages in analysis of remotely sensed datasets; but, they have limitations with the use of very high spatial resolution imagery. These techniques produce inconsistent results on very high resolution imagery which are beyond the expectations of discriminating objects of interest (Ouyang et al., 2011; Rougier et al., 2016; Xiao et al., 2016).

The development of object-oriented classification method as an alternative to pixel-based approach is suitable for remotely sensed datasets with high and very high spatial resolutions. Object-oriented classification method contributes in segmentation of imagery into groups of pixels, i.e. objects. It takes not only the spectral information, but also form and texture into account. The classification procedure begins with critical step of defining groups of neighboring pixels into significant areas which are called segments (Blaschke et al., 2000; Kuzmin et al., 2016). In this method, single pixels are not classified separately but homogeneous pixels representing objects of interest are extracted. Such segmentation step can be performed in multiple spatial resolutions to make it possible to discriminate several levels of objects. Segmentation is the first and most important step in object-oriented image classification of eCognition software (Version 8) (www.ecognition.com). The shape of each object (wild pistachio and wild almond in this study) is combined with its color and texture properties to delineate image objects properly.

Image classification starts with creating a hierarchical network of objects of interest through multi-resolution segmentations. Small objects are represented by upper-level segments, while large objects are shown by lower-level segments. In the next step, the neighborhood relationships were used to detect similar segments based on sample areas. The delineated objects are then grouped based on their physical properties, i.e. shape, color and texture of crowns of studies species. Finally, the classified objects are aggregated into homogeneous groups. The combined groups, i.e. segments or crowns of wild pistachio trees and wild almond shrubs, are then considered for further processes (Yan et al., 2006; Ouyang et al., 2011; Lu and He, 2017).

In segmentation step, it is necessary to determine three parameters of scale, color/shape, and smoothness/compactness as accurate as possible. Scale parameter influences the size of objects indirectly and determines the acceptable heterogeneity of objects. As scale parameter increases, objects become larger. Color/shape parameter assigns the effect of color vs. shape homogeneity on object delineation. When shape criterion increases, spectral information has less effect on object extraction. Smoothness/compactness parameter determines the compactness of object when the amount of shape criterion is 
considered larger than zero. The eCognition offers two separate procedures to delineate objects of interest. In this study, we used nearest neighbor and determined some samples to detect the objects, i.e. wild pistachio and wild almond.

The performance of object-oriented classification method on UAV orthoimagery was evaluated by a confusion matrix constructed by 200 randomly selected wild pistachios (100 trees) and wild almonds (100 shrubs). For validation of results, indices of accuracy (Eq. 1), precision (Eq. 2), sensitivity (Eq. 3), and specificity were applied (Eq. 4):

Accuracy $=\frac{\mathrm{TP}+\mathrm{TN}}{\mathrm{P}}$

Precision $=\frac{\mathrm{TP}}{\mathrm{TP}+\mathrm{FP}}$

Sensitivity $=\frac{\mathrm{TP}}{\mathrm{TP}+\mathrm{FN}}$

Specificity $=\frac{\mathrm{TN}}{\mathrm{TN}+\mathrm{FP}}$

where, $\mathrm{P}$ is the total number of samples (200 in here), TP is the number of samples correctly assigned to the class of interest, $\mathrm{TN}$ is the number of samples correctly assigned to other classes, FP is the number of samples that are incorrectly assigned to the class of interest, $\mathrm{FN}$ is the number of samples that are incorrectly assigned to other classes. Also, in this study Cohen's Kappa index $(\kappa)$ was used to assess the reliability of the applied classification method.

$\kappa=\frac{p_{\mathrm{o}-} \mathrm{p}_{\mathrm{e}}}{1-\mathrm{p}_{\mathrm{e}}}$

$\mathrm{p}_{\mathrm{o}}=\mathrm{TP}+\mathrm{TN}$

$\mathrm{p}_{\mathrm{e}}=(\mathrm{TP}+\mathrm{FN})(\mathrm{TP}+\mathrm{FP})+(\mathrm{FP}+\mathrm{TN})(\mathrm{TN}+\mathrm{FN})$

where, $p_{o}$ and $p_{e}$ are observed and expected agreements, respectively (Franklin, 2001; Alatorre et al., 2011).

\section{RESULTS}

The study area was covered by 1,076 images with spatial resolution of $3.47 \mathrm{~cm}$ taken by Phantom- $4 \mathrm{UAV}$. The images were georeferenced by 12 GCPs with RMSE of $8 \mathrm{~cm}$ (Fig. 5).

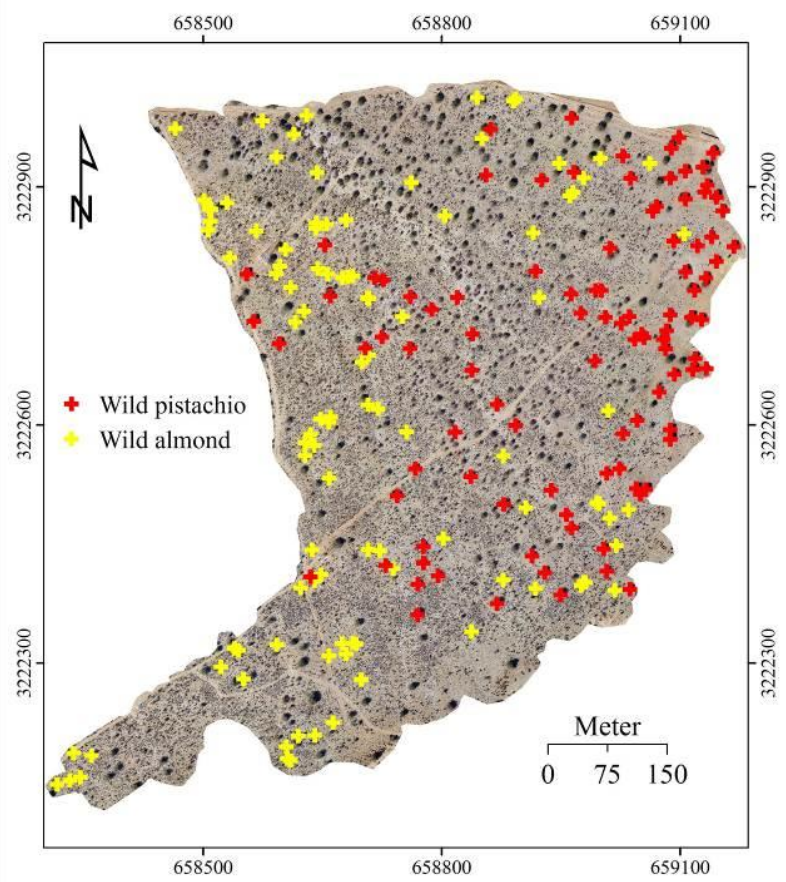

Figure 5. The UAV orthoimagery of the study area with spatial resolution of $3.5 \mathrm{~cm}$ (orthorectification $\mathrm{RMSE}=8 \mathrm{~cm}$ ). Red and yellow crosses indicate 100 random wild pistachios and 100 wild almonds selected for assessment of the results.

The UAV orthoimagery was splitted into homogeneous segments by object-oriented classification method using scale parameter of 30, color/shape parameter of 0.5 , and smoothness/compactness parameter of 0.9 . These parameters were optimized for similar conditions in another investigation. Due to the great number of segments automatically generated on the UAV orthoimagery of the study area, it was not feasible to exhibit all segments in one layer. Therefore, Fig. 6a presents a small subset of the orthoimagery and the corresponding segments. Following the segmentation process and merging the homogeneous segments, the objects were converted into vector polygons and the area of each polygon was calculated for further analyses. All trees and shrubs and their type of species were well delineated during the classification process, as illustrated in Fig. 6b.
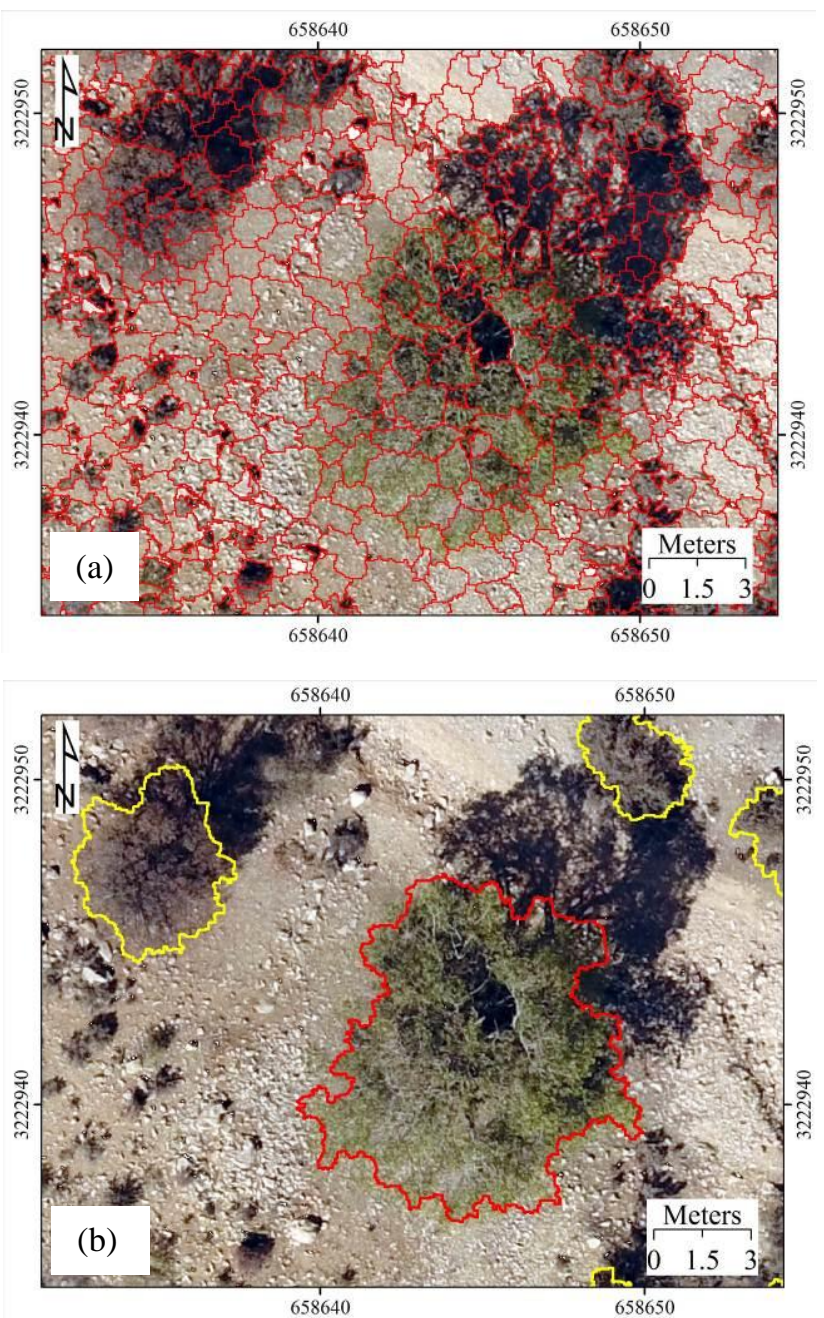

Figure 6. Segmentation used to discriminate crowns of wild pistachio trees and wild almond shrubs on the UAV orthoimagery. (a) A sample of splitting the UAV orthoimagery into segments, (b) The results of merging the segments to obtain vector map of crowns of studied species (red polygon: wild pistachio, yellow polygons: wild almond).

In the first step, 100 random wild pistachio trees and 100 random wild almond shrubs were selected within the study area 
to assess the accuracy of crown area delineation (Fig. 5). The crown area of individual tree estimated by segmentation of the UAV orthoimagery was compared with observed crown area in field measurements (Fig. 7). The validation of results showed that the predicted and observed crown areas of wild pistachios $\left(\mathrm{R}^{2}=0.86\right)$ and wild almonds $\left(\mathrm{R}^{2}=0.82\right)$ were highly correlated. Moreover, there was no significant difference between mean ( \pm standard deviation) predicted and mean ( \pm standard deviation) observed crown area of wild pistachio trees $\left(52.09 \pm 24.67 \mathrm{~m}^{2}\right.$ and $56.74 \pm 24.49 \mathrm{~m}^{2}$, respectively) ( $p$-value $=0.182$ ). Similarly, mean ( \pm standard deviation) predicted and mean $( \pm$ standard deviation) observed crown area of wild almonds were not significantly different $\left(3.97 \pm 1.69 \mathrm{~m}^{2}\right.$ and $3.80 \pm 1.86 \mathrm{~m}^{2}$, respectively) $(p$-value $=0.499)(\alpha=0.05)$.
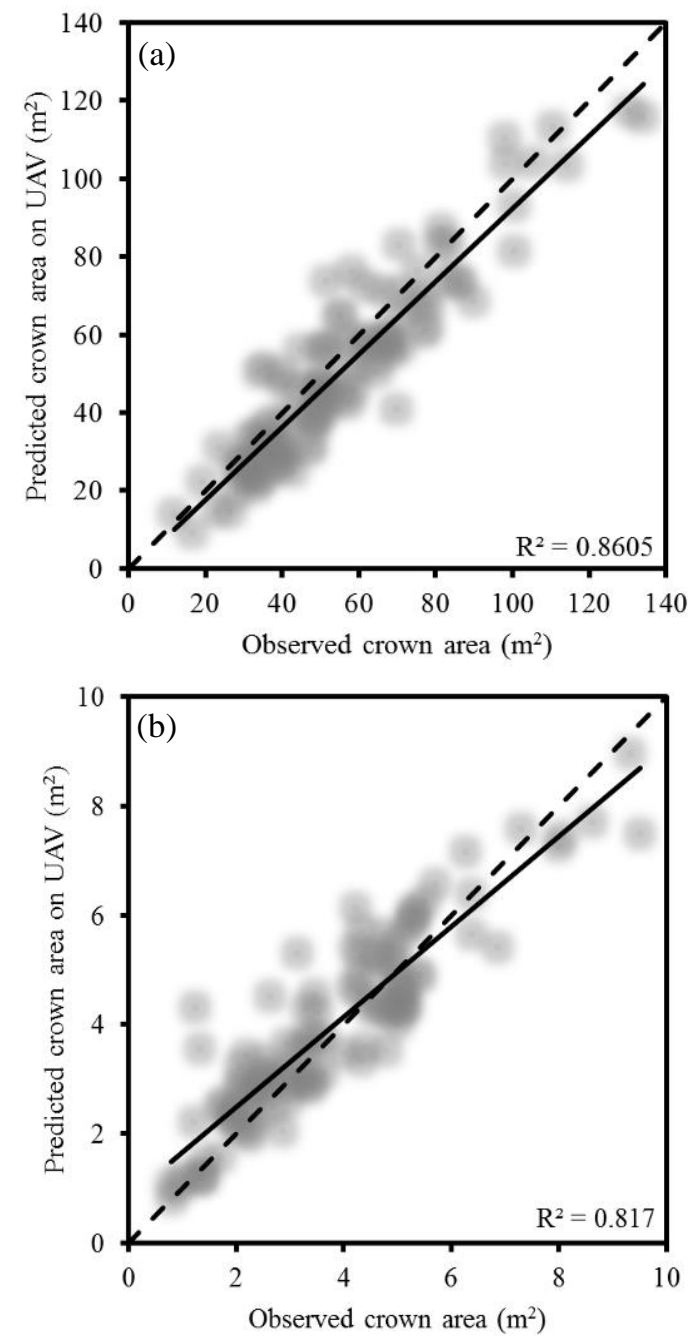

Figure 7. Predicted vs. observed crown area of 100 randomly selected wild pistachios (a) and 100 randomly selected wild almonds (b). Solid lines are the linear regression lines and dotted lines are the 1:1 lines.

In the second step, the 200 randomly selected wild pistachios and wild almonds were used to evaluate species recognition by the classification procedure. Although, the accuracy of species recognition was similar in both studied species (0.90), the precision was higher in wild pistachio (0.92), followed by wild almond (0.89). Wild pistachios had higher specificity (0.92) and less sensitivity (0.89) compared to specificity (0.89) and sensitivity of wild almonds (0.92), indicating that wild almonds were classified more correctly than wild pistachios. In addition, Cohen's Kappa index explained a significant agreement between recognized and observed species individuals of wild pistachio and wild almond (Table 2).

\begin{tabular}{|lcc|}
\hline Indices & Wild pistachio & Wild almond \\
\hline TP & 92 & 89 \\
FP & 8 & 11 \\
FN & 11 & 8 \\
TN & 89 & 92 \\
Accuracy & 0.90 & 0.90 \\
Precision & 0.92 & 0.89 \\
Sensitivity & 0.89 & 0.92 \\
Specificity & 0.92 & 0.89 \\
$\kappa$ & 0.99 & 0.99 \\
\hline
\end{tabular}

Table 2. The indices applied for performance assessment of object-oriented classification method on UAV orthoimagery to delineate wild pistachios and wild almonds (Total number of samples=200).

\section{CONCLUSION}

Vegetation maps exhibiting the present status of biometric characteristics of plant species (e.g., spatial distribution of canopy cover, types of species) are critical datasets essential for sustainable management and monitoring of valuable vegetation cover in Zagros arid and semi-arid woodlands (Owji and Hamzepour, 2012; SaghebTalebi et al., 2014). In order to produce these maps, laborious and intensive field measurements is necessary. However, it is not possible to collect such data with appropriate temporal and spatial resolution in vegetation cover distributed in large areas, e.g. Zagros open woodlands. In such conditions, remotely sensed datasets offer economical and practical tools for mapping vegetation cover (Franklin, 2001; Schowengerdt, 2007). This research was aimed to map single species of Zagros Woodlands applying orthoimagery taken by UAVs.

In the first step, the UAV orthimagery was obtained with spatial resolution of $3.47 \mathrm{~cm}$. Previous investigations indicated that the spatial resolution of orthoimagery significantly influences on the accuracy of crown delineation of trees (Ouyang et al., 2011). Therefore, flight mission was planned to acquire images with very high spatial resolution appropriate for discrimination of single trees and shrubs in the study area. This was consistent with previous studies on application of UAVs to map vegetation cover (Dandois and Ellis, 2013; Cunliffe et al., 2016; Ivosevic et al., 2017).

The UAV orhoimagery was classified by object-oriented classification method optimized in another study. The scale parameter determines the heterogeneity allowed for delineated tree crowns (i.e., 30 in this study) which indirectly controls the size of crowns delineated by classification method. As wild pistachio trees with large crown area have been observed in the study area, it seems necessary to reduce color/shape parameter to represent variation of height distribution better. In addition, larger amount of compactness/smoothness parameter (i.e., 0.9 in the present study) makes delineation of tree crowns possible more efficiently (Kuzmin et al., 2016; Piazza et al., 2016; Trang et al., 2016). However, more detailed investigations reveal the optimized amounts of these parameters to recognize wild pistachios and wild almonds due to different canopy structure of these two species.

A comparison with mean crown areas of studied species from field observations and object-oriented classification of UAV orthoimagery revealed that there was no significant 
difference between estimated and observed mean crown areas of both species. This outcome was also confirmed by linear regression analyses of estimated and observed crown area values of 200 random samples $\left(\mathrm{R}^{2}=0.86\right.$ for wild pistachio and $\mathrm{R}^{2}=0.82$ for wild almond). It also has been concluded previously that UAV orthoimagery is an appropriate means to estimate crown area of single trees (Chianucci et al., 2016). Moreover, classification of wild pistachios and wild almonds exhibited excellent discrimination accuracy ( 0.90 and 0.90 , respectively) and precision (0.92 and 0.89 , respectively), indicating that the types of species were well characterized by object-oriented classification on the UAV orthoimagery of study area. This was in accordance with the findings of previous studies on species recognition from remotely sensed datasets with very high spatial resolution (Åkerblom et al., 2017).

Thus, the results of the present study revealed that very high resolution orthoimagery obtained by UAVs are valuable datasets for detailed mapping of vegetation cover in open woodlands at single-tree levels. In addition, our findings indicated that application of object-oriented classification method on UAV orthoimagery provides a reliable tool for species recognition and canopy cover estimation of single species in open woodlands with low diversity.

\section{REFERENCES}

Åkerblom, M., Raumonen, P., Mäkipää, R. and Kaasalainen, M., 2017. Automatic tree species recognition with quantitative structure models. Remote Sensing of Environment, 191, pp. 112.

Alatorre, L.C., Andrés, R., Cirujano, S., Beguería, S. and Carrillo, S., 2011. Identification of mangrove areas by remote sensing: The ROC curve technique applied to the Northwestern Mexico coastal zone using Landsat imagery. Remote Sensing, 3, pp. $1568-1583$.

Blaschke, T., Lang, S., Lorup, E., Strobl, S., and Zeil, P., 2000. Object-oriented image processing in an Integrated GIS/remote sensing environment and perspectives for environmental application. Environmental Information for Planning, 2, pp. $555-559$.

Blaschke, T. and Strobl, J., 2001. What's wrong with pixels? Some recent developments interfacing remote sensing and GIS. GeoBIT/GIS, 6, pp. 12-17.

Carreiras, J., Pereira, J. and Pereira, J., 2006. Estimation of tree canopy cover in evergreen oak woodlands using remote sensing. Forest Ecology and Management, 223, pp. 45-53.

Chianucci, F., Disperati, L., Guzzi, D., Bianchini, D., Nardino, V., Lastri, C., Rindinella, A. and Corona, P., 2016. Estimation of canopy attributes in beech forests using true colour digital images from a small fixed-wing UAV. Applied Earth Obsevation and Geoinformation, 47, pp. 60-68.

Chopping, M., Moisen, G.G., Su, L., Laliberte, A., Rango, A., Martonchik, J.V. and Peters, D.P.T., 2008. Large area mapping of southwestern forest crown cover, canopy height, and biomass using the NASA multiangle imaging spectro-radiometer. Remote Sensing of Environment, 112, pp. 2051-2063.

Colomina, I. and Molina, P., 2014. Unmanned aerial systems for photogrammetry and remote sensing. ISPRS Journal of
Photogrammetry and Remote Sensing, 92, pp. 79-97.

Cunliffe, A.M., Brazier, R.E. and Anderson, K., 2016. Ultrafine grain landscape-scale quantification of dryland vegetation structure with drone-acquired structure-from-motion photogrammetry. Remote Sensing of Environment, 183, pp. 129-143.

Dandois, P. and Ellis, E.C., 2013. High spatial resolution threedimensional mapping of vegetation spectral dynamics using computer vision. Remote Sensing of Environment, 136, pp. 259276 .

Díaz-Varela, R., de la Rosa, R., León, L. and Zarco-Tejada, P., 2014. High-resolution airborne UAV imagery to assess olive tree crown parameters using 3D photo reconstruction: Application in breeding trials. Remote Sensing, 7, pp. 42134232.

Féret, J. and Asner, G.P., 2012. Semi-supervised methods to identify individual crowns of lowland tropical canopy species using imaging spectroscopy and LiDAR. Remote Sensing, 4(8), pp. 2457-2476.

Franklin, S.E., 2001. Remote sensing for sustainable forest manangment. Lewis Publishers, New York, 407 p.

Gleason, C.J. and Im, J., 2011. A review of remote sensing of forest biomass and biofuel: options for small-area applications. GIScience \& Remote Sensing, 48 (2), pp. 141-170.

Hanberry, B.B., Yang, J., Kabrick, J.M. and He, H.S., 2012. Adjusting forest density estimates for surveyor bias in historical tree surveys. American Midland Naturalist, 167, pp. 285-306.

Ivosevic, B., Han, Y. and Kwon, O., 2017. Calculating coniferous tree coverage using unmanned aerial vehicle photogrammetry. Ecology and Environment, 41, pp. 10.

Korhonen, L., Korhonen, K.T., Rautiainen, M. and Stenberg, P., 2006. Estimation of forest canopy cover: a comparison of field measurement techniques. Silva Fennica, 40(4), pp. 577588 .

Kuzmin, A., Korhonen, L., Manninen, T. and Maltamo, M., 2016. Automatic segment-level tree species recognition using high resolution aerial winter imagery. European Journal of Remote Sensing, 49, pp. 239-259.

Lu, B. and He, Y., 2017. Species classification using Unmanned Aerial Vehicle (UAV)-acquired high spatial resolution imagery in a heterogeneous grassland. ISPRS Journal of Photogrammetry and Remote Sensing, 128, pp. 73-85.

McNeil, B., Pisek, J., Lepisk, H. and Flamenco, E., 2016. Measuring leaf angle distribution in broadleaf canopies using UAVs. Agricultural and Forest Meteorology, 218, pp. 204-208.

Mlambo, R., Woodhouse, I., Gerard, F. and Anderson, K., 2017. Structure from motion (SfM) Photogrammetry with drone data: A low cost method for monitoring greenhouse gas emissions from forests in developing countries. Forests, 8, pp. 68.

Ouyang, Z., Zhang, M., Xie, X., Shen, Q., Guo, H. and Zhao, B., 2011. A comparison of pixel-based and object-oriented 
approaches to VHR imagery for mapping saltmarsh plants. Ecological Informatics, 6, pp. 136-146.

Owji, M. and Hamzepour, M., 2012. Vegetation profile of wild pistachio experimental forest. Research Institute of Forests and Rangelands Press, Tehran. 240 p. (In Persian)

Piazza, G.A., Vibrans, A.C., Liesenberg, V. and Refosco, J.C., 2016. Object-oriented and pixel-based classification approaches to classify tropical successional stages using airborne highspatial resolution images. GIScience \& Remote Sensing, 53, pp.

Panta, M., Kim, K. and Joshi, Ch., 2008. Temporal mapping of deforestation and forest degradation in Nepal: Applications to forest conservation. Forest Ecology and Management, 256, pp. $1587-1595$

Rautiainen, M., Stenberg, P. and Nilson, T., 2005. Estimating canopy cover in Scots pine stands. Silva Fennica, 39 (1), pp. 137-142.

Rezayan, F. and Erfanifard, Y., 2016. Estimating biophysical parameters of Persian oak coppice trees using UltraCam-D airborne imagery in Zagros semi-arid woodlands. Arid Environments, 133, pp. 10-18.

Rougier, S., Puissant, A., Stumpf, A. and Lachiche, N., 2016. Comparison of sampling strategies for object-based classification of urban vegetation from very high resolution satellite images. Applied Earth Observation and Geoinformation, 51, pp. 60-73.

Sagheb Talebi, K., Sajedi, T., and Pourhashemi, M., 2014. Forests of Iran. Iranian Research Institute of Forests and Rangelands, Tehran, 152 p. (In Persian)

Schowengerdt, R.A. 2007. Remote sensing: models and methods for image processing. Academic Press, New York, 558 p.
Torres-Sanchez, F., Lopez-Granados, F. and Pena, J.M., 2015. An automatic object-based method for optimal thresholding in UAV image: Application for vegetation detection in herbaceous crops. Computers and Electronics in Agriculture, 114, pp. 4352.

Trang, N., Toan, L., Ai, T., Giang, N. and Hoa, P., 2016. Object-based vs. pixel-based classification of mangrove forest mapping in Vien An Dong Commune, Ngoc Hien District, CaMau Province using VNREDSat-1 Images. Advances in Remote Sensing, 5, pp. 284-295.

Vega, F., Ramírez, F., Siaz, M. and Rosua, F., 2015. Multitemporal imaging using an unmanned aerial vehicle for monitoring a sunflower crop. Biosystems Engineering, 132, pp. 19-27.

Wallace, C., Webb, R. and Thomas, K.A., 2008. Estimation of perennial vegetation cover distribution in the Mojave Desert using MODIS-EVI data. GIScience \& Remote Sensing, 45(2), pp. 167-187.

www.dji.com [Available on April 2017]

www.ecognition.com [Available on April 2017]

Xiao, P., Zhang, X., Wang, D., Yuan, M., Feng, X. and Kelly, M., 2016. Change detection of built-up land: A framework of combining pixel-based detection and object-based recognition. ISPRS Journal of Photogrammetry and Remote Sensing, 119, pp. 402-414.

Yan, G., Mas, J.F., Maathuis, B., Xiangmin, Z. and Van Dijk, P., 2006. Comparison of pixel-based and object-oriented image classification approaches - A case study in a coal fire area, Wuda, Inner Mongolia, China. Remote Sensing, 27(18), pp. 4039-4055. 